\title{
Article
}

\section{Channelled tablets: An innovative approach to accelerating drug release from 3D printed tablets}

Sadia, Muzna, Arafat, Basel, Ahmed, Waqar, Forbes, Robert Thomas and Albed Alhnan, Mohamed

Available at http://clok.uclan.ac.uk/20885/

Sadia, Muzna, Arafat, Basel, Ahmed, Waqar, Forbes, Robert Thomas ORCID: 0000-0003-3521-4386 and Albed Alhnan, Mohamed (2017) Channelled tablets: An innovative approach to accelerating drug release from 3D printed tablets. Journal of Controlled Release, 269 . pp. 355-363. ISSN 0168-3659

It is advisable to refer to the publisher's version if you intend to cite from the work. http://dx.doi.org/10.1016/j.jconrel.2017.11.022

For more information about UCLan's research in this area go to http://www.uclan.ac.uk/researchgroups/ and search for <name of research Group>.

For information about Research generally at UCLan please go to http://www.uclan.ac.uk/research/

All outputs in CLoK are protected by Intellectual Property Rights law, including Copyright law. Copyright, IPR and Moral Rights for the works on this site are retained by the individual authors and/or other copyright owners. Terms and conditions for use of this material are defined in the policies page.

\section{CLoK}

Central Lancashire online Knowledge www.clok.uclan.ac.uk

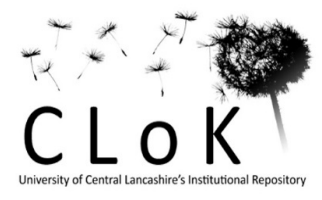




\section{Accepted Manuscript}

Channelled tablets: An innovative approach to accelerating drug release from 3D printed tablets

Muzna Sadia, Basel Arafat, Waqar Ahmed, Robert E. Forbes, Mohamed A. Alhnan

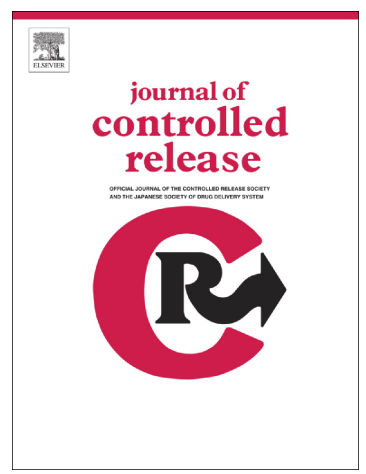

PII:

S0168-3659(17)31018-0

DOI: doi:10.1016/j.jconrel.2017.11.022

Reference: COREL 9052

To appear in: Journal of Controlled Release

Received date: 17 September 2017

Revised date: 10 November 2017

Accepted date: 12 November 2017

Please cite this article as: Muzna Sadia, Basel Arafat, Waqar Ahmed, Robert E. Forbes, Mohamed A. Alhnan, Channelled tablets: An innovative approach to accelerating drug release from 3D printed tablets. The address for the corresponding author was captured as affiliation for all authors. Please check if appropriate. Corel(2017), doi:10.1016/ j.jconrel.2017.11.022

This is a PDF file of an unedited manuscript that has been accepted for publication. As a service to our customers we are providing this early version of the manuscript. The manuscript will undergo copyediting, typesetting, and review of the resulting proof before it is published in its final form. Please note that during the production process errors may be discovered which could affect the content, and all legal disclaimers that apply to the journal pertain. 
Channelled tablets: An innovative approach to accelerating drug release from 3D printed tablets

Muzna Sadia ${ }^{1}$, Basel Arafat $^{2}$, Waqar Ahmed $^{3}$, Robert E Forbes ${ }^{1}$, Mohamed A Alhnan $^{1^{*}}$

${ }^{1}$ School of Pharmacy and Biomedical Sciences, University of Central Lancashire, UK

${ }^{2}$ Department, Medicine and Healthcare Science, Anglia Ruskin University

${ }^{3}$ College of Science/School of Mathematics and Physics, University of Lincoln, UK

*Corresponding author: MAlbedAlhnan@uclan.ac.uk 


\section{Abstract}

Conventional immediate release dosage forms involve compressing the powder with a disintegrating agent that enables rapid disintegration and dissolution upon oral ingestion. Among 3D printing technologies, the fused deposition modelling (FDM) 3D printing technique has considerable potential for patient-specific dosage form. However, the use of FDM 3D printing in tablet manufacturing requires large portion of polymer, which slows down drug release through erosion and diffusion mechanisms. In this study, we demonstrate for the first time the use of a novel design approach of caplets with perforating channels to accelerate drug release from $3 \mathrm{D}$ printed tablets. This strategy has been implemented using a caplet design with perforating channels of increasing width $(0.2,0.4,0.6,0.8$ or $1.0 \mathrm{~mm})$ and variable length, and alignment (parallel or at right angle to tablet long axis). Hydrochlorothiazide (BCS class IV drug) was chosen as model drug as enhanced dissolution rate is vital to guarantee oral bioavailability. The inclusion of channels exhibited an increase in the surface are/volume ratio, however, the release pattern was also influenced by the width and the length of the channel. A channel width $\geq 0.6 \mathrm{~mm}$ deemed critical to meet the USP criteria of immediate release products. Shorter multiple channels $(8.6 \mathrm{~mm})$ were more efficient at accelerating drug release than longer channels $(18.2 \mathrm{~mm})$ despite having comparable surface area/mass ratio. This behaviour may be linked to the reduced flow resistance within the channels and the faster fragmentation during dissolution of these tablets. In conclusion, the width and length of the channel should be carefully considered in addition to surface area/mass when optimizing drug release from $3 \mathrm{D}$ printed designs. The incorporation of short channels can be adopted in the designs of dosage forms, implants or stents to enhance the release rate of eluting drug from rich polymeric structures.

Keywords: Patient-centred; bespoke, Personalised; Patient-specific; additive manufacturing, complex geometry 


\section{Introduction}

Immediate release tablets is the most commonly used dosage form [1, 2]. This trend is likely to continue in oral drug delivery. Between 2005-2015, 79\% of new drug approvals (NDAs) for oral products were for immediate release formulations [3]. In fact, accelerating drug release from tablet has been highly desirable in oral formulations for the last few decades. Several advancements were introduced to accelerate tablet disintegration and dissolution such as super-disintegrants [4-6], effervescent [7-9] and alkaline solubiliser [10].

The first patent for compressed tablets was filed in 1843 in England in an effort to form a pill without using a large amount of binder that slows drug release [11]. The compressing powder under high pressure has since become the standard method for tablet manufacturing. The formulation design of tablets has been well-established for decades using common ingredients such as filler, binder, a gliding and disintegrant as well as a material that allow fast disintegration in the gastric environment. Later, between 1930s-1950s, in order to improve palatability, ecstatic quality and patient compliance, film coatings were introduced [12].

The principal mechanism of tablet formation remained the same until the introduction of powder based 3D printing technology, where the use of powder bed allows the binding of powders in situ to form tablets [13]. However, this has been at the expense of the ecstatic and mechanical properties of these tablets, with poor finishing, rough surface [14] and high friability value $[15,16]$. Recently, fused deposition modelling (FDM) 3D printing has been proposed as an alternative 3D printing technology for on demand fabrication of individualised dosage forms $[17,18]$ and offered several advantages. It is a low cost production unit with minimal space requirements and produces mechanically resistant tablets without the need to a finishing step [17-20].

Unlike conventionally compressed tablets, where dissolution is first initiated by tablet disintegration after water imbibition and particle swelling, the disintegration and dissolution of FDM 3D printed tablets may be dominated by erosion and diffusion mechanisms $[17,18]$. This is resulted by the use of a high percentage of polymer for filament production in hot melt extrusion HME (minimum polymer loading of $45 \% \mathrm{w} / \mathrm{w}$ ) [21]. Such polymer-rich structure has a significant effect on slowing drug release from the fabricated tablets. This might be reflected in numerous examples for extended drug release [18, 22-27]. It is the 
immediate release that is the most challenging to achieve from FDM 3D printed structures $[28,29]$.

Previous attempts investigated the effect of the external shape and volume/mass ratio of $3 \mathrm{D}$ printed tablets on the pattern of extended drug release [30]. Some efforts also exploited the infill function of FDM [17, 31], and inkjet [31] 3D printers to modify drug release. However, this approach was originally introduced to $3 \mathrm{D}$ printing to enhance the structural integrity of the printed object while minimizing the use of material. It necessitated the dissolution of the shells before media penetration and often yielded low-density floating tablets. In order to accelerate drug release from FDM 3D printed structures, an alternative solution for tablet disintegration and dissolution is essential.

In this research, we have introduced a novel tablet design with built-in channels to accelerate drug release from 3D printed polymethacylate tablets. The impact of channel width, length and position on in vitro drug release has been investigated in addition to surface area/volume ratio. This work also uniquely investigated the impact of such design on changes in 3D printing objects throughout the dissolution process and compared this solution to the traditional conventional approach of adding disintegrant. Hydrochlorothiazide, a biopharmaceutical classification system (BCS) class IV drug with poor solubility and permeability [32-34], was chosen as model drug as accelerating drug release is essential to maintain oral bioavailability.

\section{Materials and methods}

\subsection{Materials}

Hydrochlorothiazide $(\mathrm{HCT})\left(\mathrm{Tm}=268^{\circ} \mathrm{C}\right)$, triethyl citrate $(\mathrm{TEC})$ and tri-Calcium phosphate (TCP) were supplied by Sigma-Aldrich (UK). Eudragit E was donated by Evonik Industries (Darmstadt, Germany). Croscarmellose sodium (Ac-Di-Sol ${ }^{\circledR}$ and Primellose ${ }^{\circledR}$ ) was supplied by FMC Biopolymer (USA) and DFE Pharma (Germany) respectively, sodium starch glycolate $\left(\right.$ Primojel $^{\circledR}$ and Explotab $^{\circledR}$ ) were donated by DFE Pharma (Germany) and JRS pharma LP (USA) respectively, crosslinked polyvinylpyrrolidone (Polyplasdone-XL ${ }^{\circledR}$ ) was donated by Ashland (USA). Scotch Blue Painter's tape $50 \mathrm{~mm}$ was supplied by 3M (Bracknell, UK). All other agents were provided by Sigma Aldrich (UK).

2.2 Preparation and optimisation of filaments. 
An optimised ratio of Eudragit E: TEC: TCP: HCT (46.75:3.25:37.5:12.5 \%wt) was employed to produce drug loaded filaments [29]. Approximately $10 \mathrm{~g}$ of materials was accurately weighed and added gradually to counter flow twin-screw hot melt extruder, HAAKE MiniCTW (Karlsruhe, Germany). To allow homogeneous distribution of the powders, the molten mass was mixed in the extruder for at least 5 min prior to extrusion. The specific temperatures of initial feeding and extrusion for the filament were 100 and $90^{\circ} \mathrm{C}$ respectively. A torque control of $0.8 \mathrm{Nm}$ was used to extrude out the filaments. Filaments were stored in sealed plastic bags at room temperature before $3 \mathrm{D}$ printing.

For disintegrant containing filament, a ratio of Eudragit E: TEC: TCP: disintegrant: HCT 46.75:3.25:33.5:4:12.5 were used to produce individual filaments for each of the following disintegrants: Ac-Di-Sol ${ }^{\circledR}$, Primellose ${ }^{\circledR}$, Primojel $^{\circledR}$, Polyplasdone-XL $^{\circledR}$ or Explotab ${ }^{\circledR}$

\subsection{Design and printing of tablets.}

The basic shape of the tablet is based on capsule-shaped tablet (caplet) design at dimensions: $17.2 \times 6.8 \times 6.25 \mathrm{~mm}$. In order to assess the impact of tablet volume, a series of tablets of increasing tablet dimensions were designed and printed (Tablet 1). The caplet design (dimensions: $17.2 \times 6.8 \times 6.25 \mathrm{~mm}$ ) was perforated with identical channels of square section and rectangular length. The widths of channel section were $0.2,0.4,0.6,0.8$ or $1.0 \mathrm{~mm}$. The impact of the length and orientation of the channels within the caplet design was investigated by applying either a) 9-long channel parallel to the long axis of the caplet design or b) 18shorter channels at right angle to the long axis of the caplet design (Figure 2). As it was not possible to include these channels and maintain identical surface/volume ratio without fundamentally altering tablet dimensions and shape, the dimensions of the channelled tablet design were kept identical and the changes in surface area and surface to volume ratio was reported in Table 2.

Tablets were constructed with the pre-prepared filaments using a commercial FDM 3D printer with a $0.4 \mathrm{~mm}$ nozzle. The templates used to print the tablets were designed in caplet shape using Autodesk ${ }^{\circledR}$ 3ds Max-Design 2016 software version 18.0 (Autodesk, Inc., USA). The design was saved in a stereolithography (.stl) file format and imported to the 3D printer's software, MakerWare Version 2.4.0.17 (Makerbot Industries, LLC. USA). Tablets were printed using modified settings of the software for PLA filament as described in our previous work.[21] The temperature for 3D printing and build plate was $135^{\circ} \mathrm{C}$ and $60^{\circ} \mathrm{C}$ respectively and at standard resolution. As the density of the printed structure is dependant of the density 
of extruded filament and the voids between the fused filaments layers (above and beyond the channels space of the original design), it is important to maintain the same filling pattern across the different designs. Therefore, the settings of the slicing engine (infill pattern = hexagonal, infill density $=100 \%$, layer height $=200 \mu \mathrm{m}$ ) were identical for all printed designs. 
Table 1 Measured dimensions, volumes, surface area, surface to volume and surface to mass ratios of CAD designs of solid tablets (no channels).

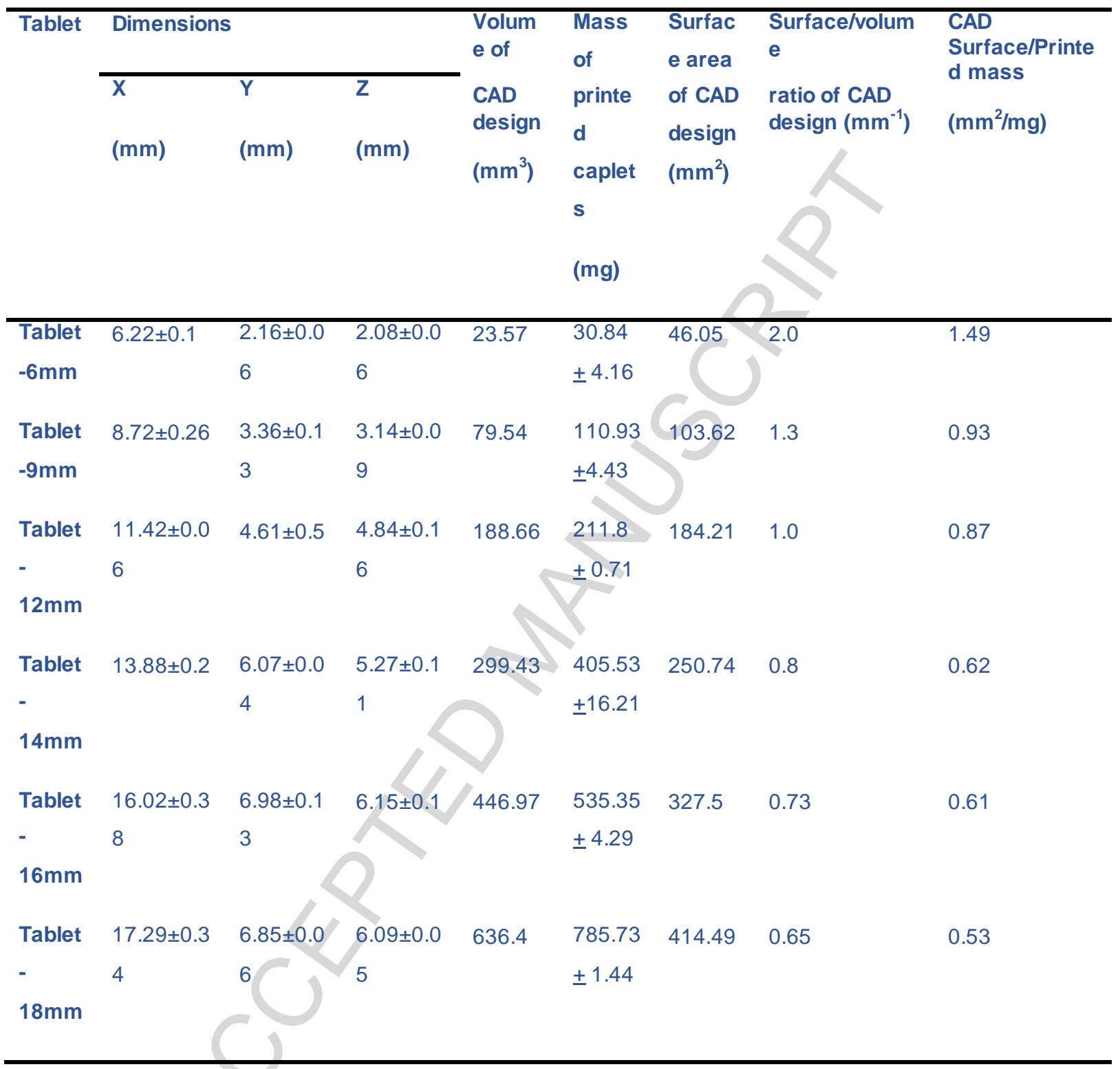


Table 2. Measured dimensions, volumes, surface area, surface to volume and surface to mass ratios of CAD designs of solid and channelled tablets

\begin{tabular}{|c|c|c|c|c|c|c|c|c|c|}
\hline \multirow{2}{*}{$\begin{array}{l}\text { Tablet } \\
\text { design }\end{array}$} & \multicolumn{3}{|c|}{ Dimensions } & \multirow{2}{*}{$\begin{array}{l}\text { Channel } \\
\text { dimensio } \\
\text { ns in CAD } \\
\text { design } \\
(\mathrm{mm})\end{array}$} & \multirow{2}{*}{$\begin{array}{l}\begin{array}{l}\text { Volum } \\
\text { e of }\end{array} \\
\text { CAD } \\
\text { desig } \\
\mathrm{n} \\
\left(\mathrm{m} \mathrm{m}^{3}\right)\end{array}$} & \multirow{2}{*}{$\begin{array}{l}\text { Mass } \\
\text { of } \\
\text { printe } \\
\text { d } \\
\text { caplet } \\
\text { s } \\
(\mathrm{mg})\end{array}$} & \multirow{2}{*}{$\begin{array}{l}\text { Surfac } \\
\text { e area } \\
\text { of } \\
\text { CAD } \\
\text { design } \\
\left(\mathrm{m} \mathrm{m}^{2}\right)\end{array}$} & \multirow{2}{*}{$\begin{array}{l}\text { Surface/volu } \\
\text { me } \\
\text { ratio of CAD } \\
\text { design } \\
\left(\mathrm{m} \mathrm{m}^{-1}\right)\end{array}$} & \multirow{2}{*}{$\begin{array}{l}\text { CAD } \\
\text { Surface/Print } \\
\text { ed mass } \\
\left(\mathrm{m} \mathrm{m}^{2} / \mathrm{mg}\right)\end{array}$} \\
\hline & $\begin{array}{l}X \\
(\mathrm{~mm})\end{array}$ & $\begin{array}{l}\mathrm{Y} \\
(\mathrm{mm})\end{array}$ & $\begin{array}{l}Z \\
(\mathrm{~mm})\end{array}$ & & & & & & \\
\hline $\begin{array}{l}\text { Solid } \\
\text { design } \\
\text { (no } \\
\text { channel } \\
\text { s) }\end{array}$ & $16.99 \pm 0.1$ & $\begin{array}{l}6.79 \pm 0.0 \\
1\end{array}$ & $\begin{array}{l}6.09 \pm 0.0 \\
5\end{array}$ & $\begin{array}{l}\text { No } \\
\text { channels }\end{array}$ & 553.81 & $\begin{array}{l}785.73 \\
\pm 1.44\end{array}$ & .8 & 0.682 & 0.481 \\
\hline $\begin{array}{l}9 \\
\text { channel } \\
\mathrm{s} \\
(0.2 \mathrm{~mm})\end{array}$ & $\begin{array}{l}17.07 \pm 0.1 \\
2\end{array}$ & $\begin{array}{l}6.51 \pm 0.0 \\
6\end{array}$ & $5.9 \pm 0.02$ & $0.2 \times 0.2$ & 548. & $593 \pm$ & 493.34 & 0.9 & 0.832 \\
\hline $\begin{array}{l}9 \\
\text { channel } \\
\mathrm{s} \\
(0.4 \mathrm{~mm})\end{array}$ & $\begin{array}{l}16.89 \pm 0.0 \\
3\end{array}$ & $\begin{array}{l}6.53 \pm 0.0 \\
6\end{array}$ & $5.9 \pm 0.06$ & . & 530.46 & $\begin{array}{l}579.33 \\
\pm 6.54\end{array}$ & 607.59 & 1.15 & 1.049 \\
\hline $\begin{array}{l}9 \\
\text { channel } \\
\mathrm{s} \\
(0.6 \mathrm{~mm})\end{array}$ & $\begin{array}{l}16.86 \pm 0.0 \\
6\end{array}$ & $6.7 \pm 0.07$ & 6. & 6 & 501.38 & $\begin{array}{l}591 \pm \\
5.72\end{array}$ & 718.64 & 1.43 & 1.216 \\
\hline $\begin{array}{l}9 \\
\text { channel } \\
\mathrm{s} \\
(0.8 \mathrm{~mm})\end{array}$ & $\begin{array}{l}16.78 \pm 0.0 \\
8\end{array}$ & $6.78 \pm 0.0$ & $5.9 \pm 0.02$ & $0.8 \times 0.8$ & 460.95 & $\begin{array}{l}571.33 \\
\pm 0.53\end{array}$ & 825.89 & 1.79 & 1.446 \\
\hline $\begin{array}{l}9 \\
\text { channel } \\
s(1 \mathrm{~mm})\end{array}$ & $\begin{array}{l}16.78 \pm 0.1 \\
4\end{array}$ & $\begin{array}{l}6.63 \pm 0.1 \\
1\end{array}$ & $6.0 \pm 0.09$ & $1 \times 1$ & 408.25 & $\begin{array}{l}546.67 \\
\pm 4.89\end{array}$ & 934.75 & 2.29 & 1.710 \\
\hline $\begin{array}{l}18 \\
\text { channel } \\
\mathrm{s} \\
(0.2 \mathrm{~mm})\end{array}$ & $\begin{array}{l}16.98 \pm 0.0 \\
9\end{array}$ & $\begin{array}{l}6.52 \pm 0.0 \\
2\end{array}$ & $6.0 \pm 0.12$ & $0.2 \times 0.2$ & 549.07 & $\begin{array}{l}552 \pm \\
3.62\end{array}$ & 471.19 & 0.86 & 0.854 \\
\hline $\begin{array}{l}18 \\
\text { channel } \\
\mathrm{s} \\
(0.4 \mathrm{~mm})\end{array}$ & $\begin{array}{l}16.97 \pm 0.0 \\
2\end{array}$ & $\begin{array}{l}6.66 \pm 0.0 \\
1\end{array}$ & $5.9 \pm 0.04$ & $0.4 \times 0.4$ & 534.81 & $\begin{array}{l}639.33 \\
\pm 1.54\end{array}$ & 561.53 & 1.05 & 0.878 \\
\hline $\begin{array}{l}18 \\
\text { channel }\end{array}$ & $\begin{array}{l}16.96 \pm 0.0 \\
7\end{array}$ & $\begin{array}{l}6.65 \pm 0.0 \\
4\end{array}$ & $6.1 \pm 0.05$ & $0.6 \times 0.6$ & 511.19 & $\begin{array}{l}604 \pm \\
1.79\end{array}$ & 647.5 & 1.27 & 1.072 \\
\hline
\end{tabular}




\begin{tabular}{|c|c|c|c|c|c|c|c|c|c|}
\hline 18 & $16.89 \pm 0.0$ & $6.6 \pm 0.08$ & $6.2 \pm 0.02$ & $0.8 \times 0.8$ & 478.44 & 547.33 & 728.17 & 1.52 & 1.330 \\
\hline channel & 8 & & & & & \pm 2.77 & & & \\
\hline \multicolumn{10}{|l|}{$\mathbf{s}$} \\
\hline \multicolumn{10}{|l|}{$(0.8 \mathrm{~mm})$} \\
\hline 18 & $16.68 \pm 0.0$ & $6.6 \pm 0.02$ & $6.21 \pm 0.1$ & $1 \times 1$ & 436.91 & 540.67 & 802.4 & 1.84 & 1.484 \\
\hline channel & 7 & & & & & \pm & & & \\
\hline $\mathrm{s}(1 \mathrm{~mm})$ & & & & & & 11.21 & & $p$ & \\
\hline
\end{tabular}

\subsection{Thermal analysis.}

Samples (raw materials, extruded filaments and printed tablets) were characterised using differential scanning calorimetry (DSC) and thermogravimetric analysis (TGA). For DSC analysis, a differential scanning calorimeter DSC Q2000 (TA Instruments, Elstree, Hertfordshire, UK) with a heating rate of $10{ }^{\circ} \mathrm{C} / \mathrm{min}$ was used. Samples were first cooled to $-50{ }^{\circ} \mathrm{C}$ followed by an isotherm for 1 minute and then heat scan from -50 to $300{ }^{\circ} \mathrm{C}$. Analysis was carried out under a nitrogen $(50 \mathrm{~mL} / \mathrm{min})$ purge. The data was analysed using TA 2000 analysis software. Tzero TA aluminium pans and Tzero hermetic lids were used with an approximate sample mass of $7 \mathrm{mg}$. All measurements were carried out in triplicates.

For TGA analysis, raw materials, model drug, extruded filaments and 3D printed tablets were measured using a TGA Q500 (TA Instruments, Elstree, Hertfordshire, UK). Samples (7 mg) were placed in $40 \mu \mathrm{L}$ aluminium pans and then heated from 25 to $500^{\circ} \mathrm{C}$ using a heating rate of $10^{\circ} \mathrm{C} / \mathrm{min}$. The thermal decomposition (or degradation) profile was analysed using TA 2000 analysis software. The experiments were carried out under nitrogen gas flow of $50 \mathrm{~mL} / \mathrm{min}$. All measurements were carried out in triplicates.

\subsection{X-ray Powder diffractometry (XPRD).}

A powder X-ray diffractometer, D2 Phaser with Lynxeye (Bruker, Germany) was used to assess the physical form of model drugs in Eudragit E, TCP, Eudragit E:TEC filament, blank and drug-loaded filaments, and 3D printed tablets. Samples were scanned from $2 \mathrm{Theta}=5^{\circ}$ to $50^{\circ}$ using $0.01^{\circ}$ step width and a 1 second time count. The divergence slit was $1 \mathrm{~mm}$ and the scatter slit $0.6 \mathrm{~mm}$. The wavelength of the $\mathrm{X}$-ray was $0.154 \mathrm{~nm}$ using $\mathrm{Cu}$ source and a voltage 
of $30 \mathrm{kV}$. Filament emission was $10 \mathrm{~mA}$ using a scan type coupled with a two theta/theta scintillation counter over $30 \mathrm{~min}$.

\subsection{Scanning Electron Microscopy}

The surface morphology of the filaments and the printed tablets was assessed using a Quanta200 SEM microscope at $20 \mathrm{kV}$. All samples for SEM visualisation were placed on a metallic stub and gold plated using a JFC-1200 Fine Coater (Jeol, Tokyo, Japan). Photographs of the tablets were captured with a Canon EOS-1D Mark IV (Canon Ltd, Japan).

\subsection{X-ray micro-computed tomography $(\mathrm{X} \mu \mathrm{CT})$}

A SkyScan1172 high-resolution X-ray micro computed tomography $(\mathrm{X} \mu \mathrm{CT})$ scanner (Bruker-microCT, Belgium) was utilized to analyse the internal structure of the channelled tablet.

\subsection{Characterisation of the tablets properties}

In order to assess the impact of channelled design on the mechanical properties of the tablets, 20 tablets were randomly selected, weighed and placed in a friability Tester Erweka type TAR 10 (Erweka GmbH, Heusenstamm, Germany) and the drum was then rotated at $25 \mathrm{rpm}$ for $4 \mathrm{~min}$. The tablets were reweighed and the differences in weight were calculated and displayed as a percentage of the original sample weight. Drug contents in the samples were assessed using an Agilent UV-HPLC 1260 series (Agilent Technologies, Inc., Germany) equipped with Kinetex C18 column $(100 \times 2.1 \mathrm{~mm}$, particle size $2.6 \mu \mathrm{m})$ (Phenomenex, Torrance, USA). The mobile phase was (acetonitrile: water adjusted $\mathrm{pH} 3$ with orthophosphoric acid) at ratio $70: 30$ and a flow rate of $0.5 \mathrm{~mL} / \mathrm{min}$. The injection volume was $20 \mu \mathrm{L}$ and stop time was $5 \mathrm{~min}$ per sample. The wavelength was set to $230 \mathrm{~nm}$ at $37^{\circ} \mathrm{C}$ and retention time of the drug was $2.75 \mathrm{~min}$. The method showed linearity between $1-100 \mathrm{mg} / \mathrm{L}$ with $\mathrm{R}^{2}=0.996$ and limits of detection and quantification of 0.1 and $2.5 \mathrm{mg} / \mathrm{L}$ respectively. The accuracy was $107.1 \% \pm 5.1$ and $97 \% \pm 0.5$ at concentrations: 12.5 and $37.5 \mathrm{mg} / \mathrm{L}$ respectively.

\subsection{In vitro Dissolution test of the tablets}

Drug release studies carried out using a USP II Erweka DT600 dissolution tester (Erweka GmbH, Heusenstamm, Germany). Three tablets were randomly selected and individually placed in the dissolution vessels each containing $900 \mathrm{~mL}$ of $0.1 \mathrm{M} \mathrm{HCl}$ at $50 \mathrm{rpm}$ and $37 \pm 0.5$ 
${ }^{\circ} \mathrm{C}$. Aliquots $(4 \mathrm{~mL})$ were manually collected using $5 \mathrm{ml}$ Leur-Lock syringes at $0,5,10,15$, 20, 25, 30, 40, 50 and 60 minutes time intervals and filtered through a Millex-HA $0.45 \mu \mathrm{m}$ filter. Each aliquot withdrawn was replaced with $4 \mathrm{~mL}$ of $0.1 \mathrm{M} \mathrm{HCl}$. The absorbance of hydrochlorothiazide was finally measured using a Jenway UV spectrophotometer (Bibby Scientific Ltd, UK) at $\lambda_{\max }$ of $278 \mathrm{~nm}$. All dissolution test were carried out in triplicates. In order to assess the disintegration behaviour of the 3D printed tablet during dissolution test, the dissolution test has been video recorded using a Sony HXR-NX3 camera (Sony Electronics Inc., Japan) with the macro option on. Wide-angle green laser probes were used to illuminate the tablets during dissolution in a dark room. All dissolution test were carried out under sink condition [35].

\subsection{Statistical analysis}

One-way ANOVA was employed using SPSS Software (22.0.0.2) to analyse the differences in the percentages of drug release at $\mathrm{T}=30 \mathrm{~min}$. Differences in results between $p \leq 0.05$ were considered significant, $p$ of 0.05 was considered not significant.

\section{Results and discussion}

Thiazide diuretic methacrylate tablets were produced using FDM 3D printing using Eudragit E based filament as the feed ink. Thermal analysis indicated that the filament is stable at the preparation temperature (Figure S1a) and flexible with a $\mathrm{Tg}$ of $29.5{ }^{\circ} \mathrm{C}$ (Figure S1b). X-ray diffraction spectra (Figure S1c) confirmed that a portion of hydrochlorothiazide was crystalline with the appearance of peak at 2 Theta $=19.15^{\circ}$ and $28.7^{\circ}[36]$.

The poly-methacrylate tablets with a solid design (no channels) and increasing tablet volume were 3D printed. The USP dissolution result illustrated that the drug release rate slowed down with increased volume (Figure 1a, Table 1). This may be due to the reduced surface/mass ratio of the larger tablets. As drug release from polymeric matrix is mainly governed by erosion and diffusion mechanism [37-39], a slower release was expected due to the smaller surface area/mass ratio. 


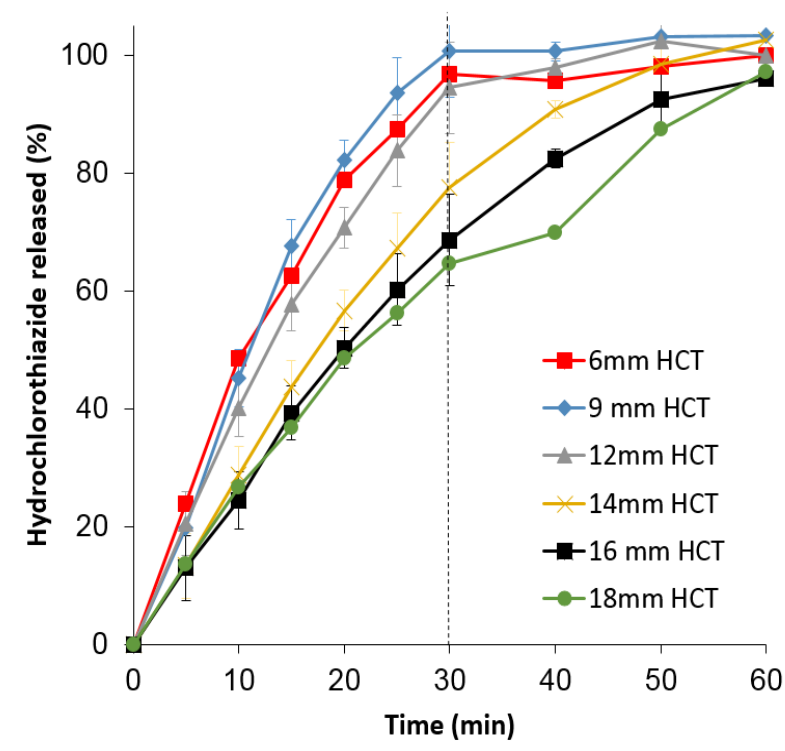

b

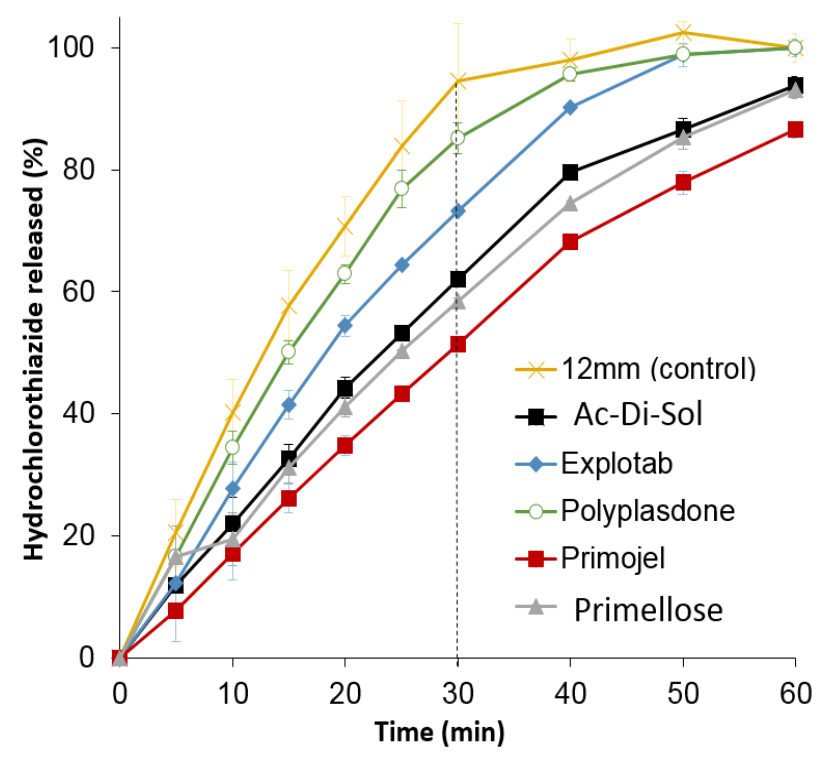

Figure 1. Impact of caplet dimensions and inclusion of disintegrant on in vitro drug release from 3D printed tablets (solid design). a) In vitro release of hydrochlorothiazide from different sizes of Eudragit $E$ tablets, the percentages of drug release at $\mathrm{T}=30 \mathrm{~min}$ were considered as functionality outcome, one way ANOVA, $P<0.05$ (mean $\pm S D, n=3$ ), b) in vitro release of hydrochlorothiazide from Eudragit $E$ caplets with/without commercially available disintegrants (mean $\pm S D, n=3$ ). 
An established approach to accelerate drug release from tablet is through the incorporation of a disintegrant. Different disintegrants were added in the tablet formation; however, they seemed to add little to accelerating drug release (Figure 1b). With their porous structure, disintegrants function by increasing water uptake into the tablet and elevating the internal pressure trough swelling $[40,41]$. The inability of the disintegrant to induce tablet disintegration and in turn to accelerate drug release may be due to the relatively excessive percentage of the polymer in the tablet matrix. During the thermal processing of HME, it is possible that the liquefied polymer has coated the disintegrant particles, sealed their pores and restricted their swelling during dissolution test. Further increase in disintegrant resulted in a difficult-to-print filament and did not favour dissolution (unpublished work).

A schematic diagram of design of 3D printed tablet with built-in channels is shown in Figure 2. Tablets were crafted in an easy-to-swallow caplet design. In order to accelerate drug release, the design has been perforated with square channels of increasing widths. Two orientations of the channels were proposed either parallel to the caplet's long axis or at right angle to the axis. In order to maintain a comparable surface/volume ratios, a larger number of shorter channels were incorporated.

The images of rendered tablet designs and photos of actual tablet with increasing built-in channels are shown in Figure 3. The printed structures maintained their shape, form and structure. The tablet remained mechanically resistant with a friability value of zero, hence indicating that the inclusion of channels did not alter the product's suitably to handle and swallow. 

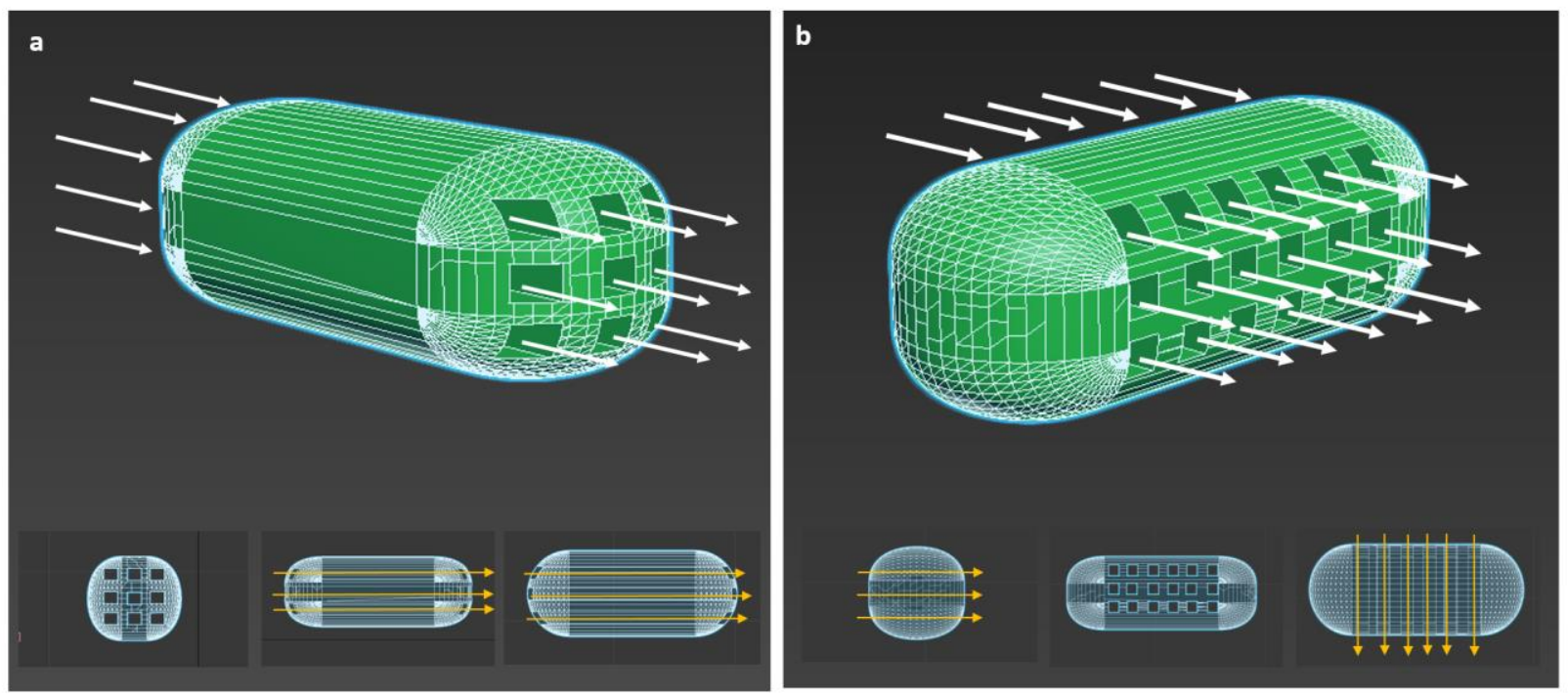

Figure 2. Schematic illustration concept of perforating square sectioned channels. The dissolution medium will perforate through the channels and accelerate tablet disintegration and dissolution. The perforating channels were a1) parallel to long axis (9 long channels) or b1) at right angle with the long axis with 3D max rendered images of frontal, side and top view of channelled tablet designs.
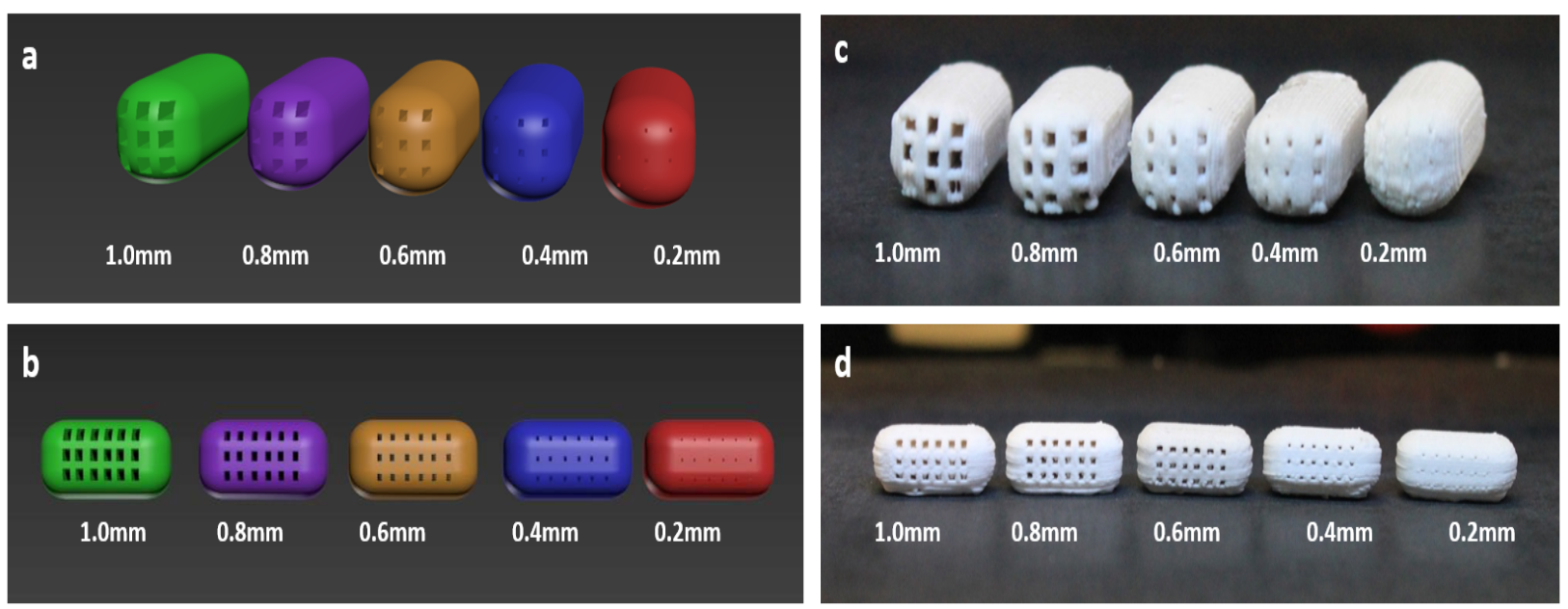

Figure 3. Rendered images of tablet designs with decreasing channel size with a) 9-long channels b) 18-short channels, photographs of tablets with decreasing channel size c) 9 long channels d) 18 short channels.

In order to gain a better understanding of the internal structure of the tablets, $\mathrm{X} \mu \mathrm{CT}$ technique was employed (Figures 4-5). For $1.2 \mathrm{~mm}$ channelled tablet, it is evident that the channel height is made of 5 channels each is $200 \mu \mathrm{m}$ high. The upper surface of each channel within the tablet showed some downward facing curvatures and bends as opposed to the lowed surface. This deformation might be related to the absence of the support for the weight of this 
area during the solidification of the fusing layers. Such a deformation is also noted when 18short short channels were 3D printed.
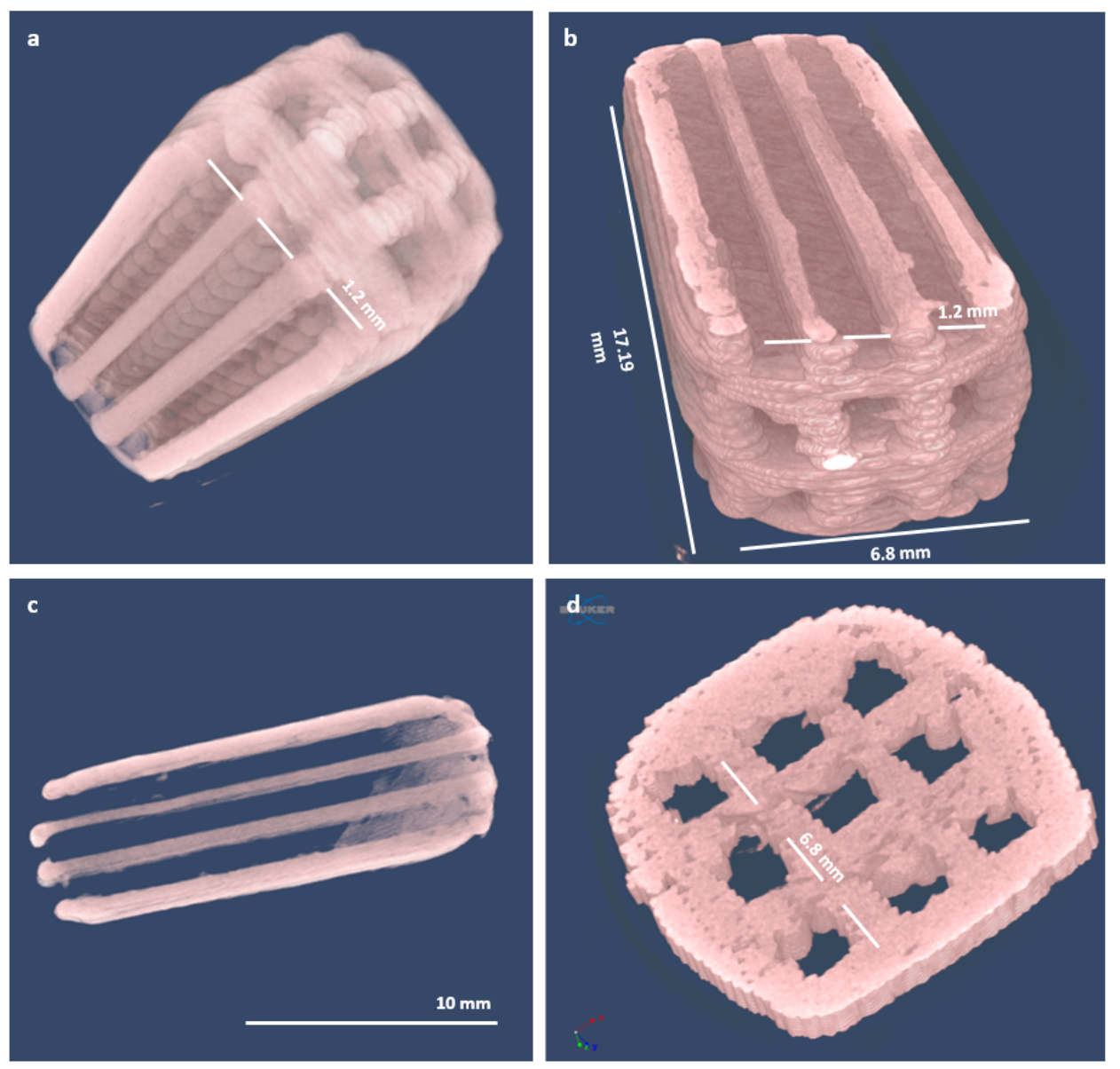

Figure 4. Visualisation of X XCT data of 9-long channel design with $1 \mathrm{~mm}$ channel. View of the internal structure of the internal surface of the channel from (a) bottom and (b) top, c) X-Y section and d) Y-Z section of the long channels across the tablets. 

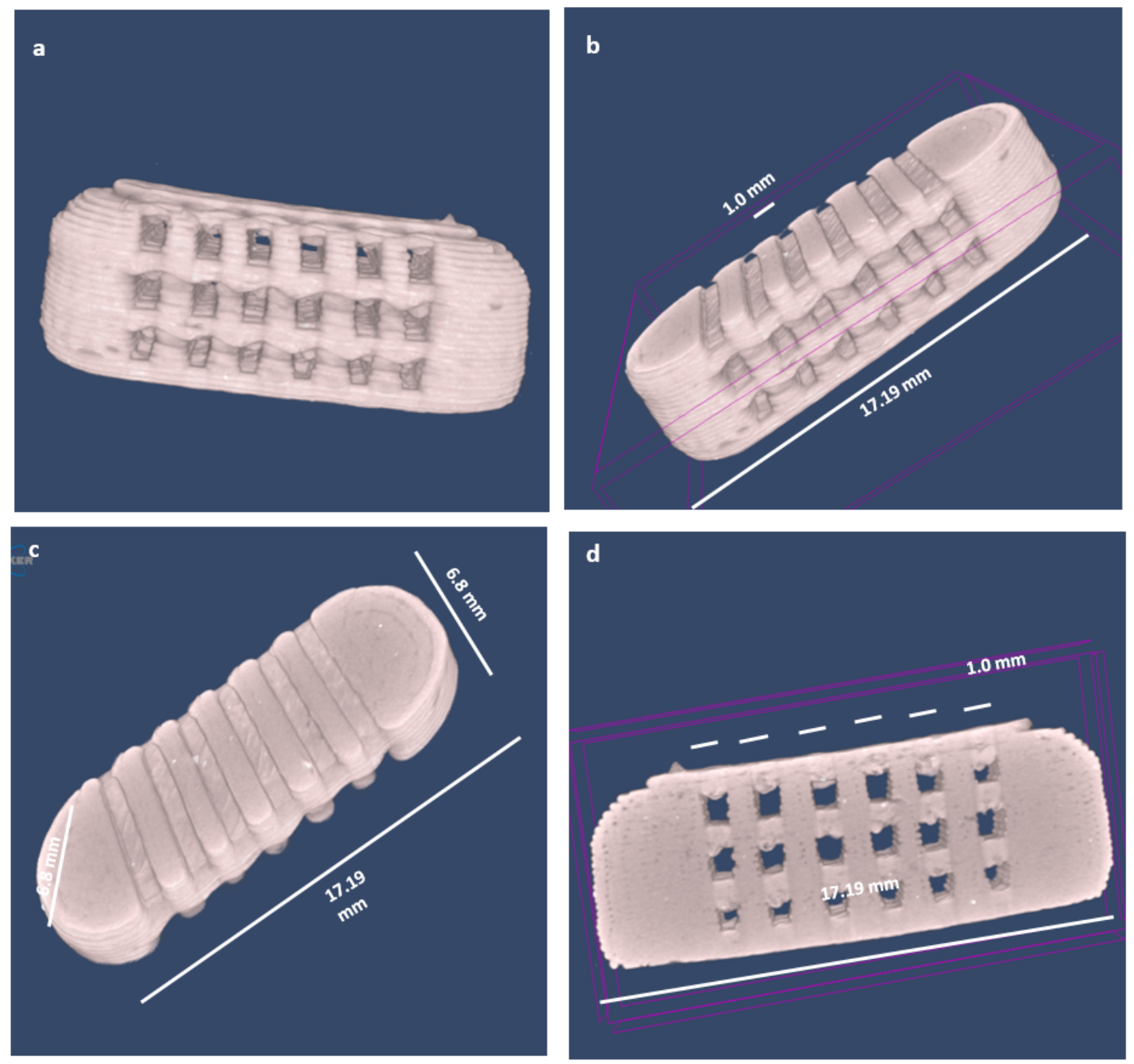

Figure 5. Visualisation of X X CT data of 18-short channel design with $1 \mathrm{~mm}$ channels. a) Side view of the tablet, b) view of the top, c) $X-Y$ section and d) $X-Z$ section of the channels across the tablets.

The impact of design on in vitro drug release from the constructed tablet showed slow release from block tablets (Figure 6). When short channels of 0.2-0.4 $\mathrm{mm}$ channel were used, a limited improvement of dissolution rate was noticed. However, increasing the channel width to $0.8-1.0 \mathrm{~mm}$ led to a significant increase in theophylline release at $\mathrm{T}=30 \mathrm{~min}$, reaching $78.7 \%, 88.5 \%$ and $92.3 \%$ for 9-long channel design, and $85 \%, 93.4 \%$ and $93.4 \%$ for 18 -short channelled design. It is important to highlight that such an increase in percentage of drug release with channelled tablets was critical to meet pharmacopeial criteria of immediate release tablets. 

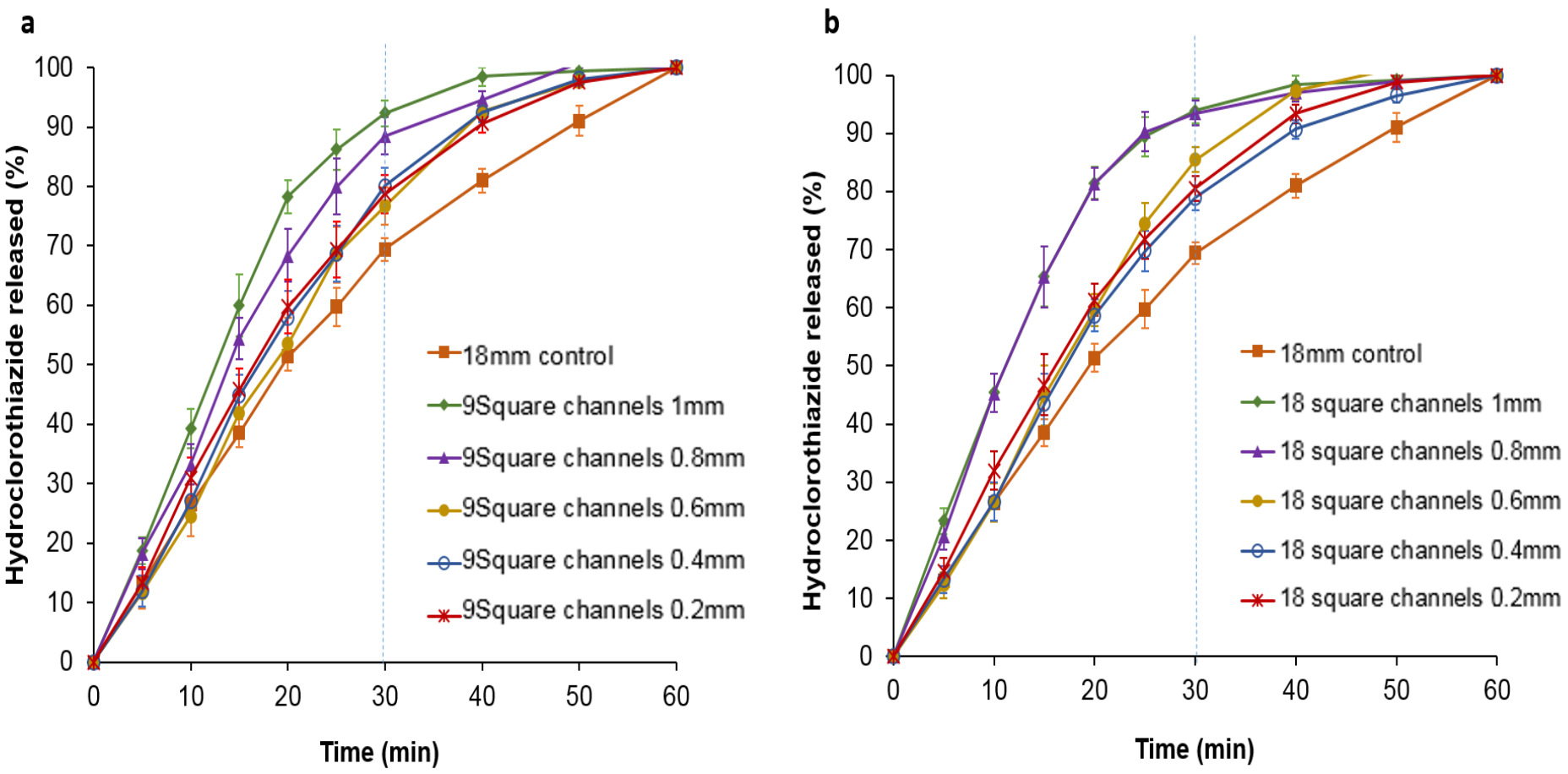

Figure 6. Impact on channel width and orientation on dissolution release pattern from hydrochlorothiazide methacrylate tablet in USP II dissolution test in gastric medium $(0.1 \mathrm{M} \mathrm{HCl} \mathrm{pH}$ $1.2,50 \mathrm{rpm}$. Average $\pm \mathrm{SD}$ ) a) 18 long tablets, and b) short tablets.

Several literature reports directly linked the increase in dissolution rate to an increase in the total surface area in multi-units [42-44] and 3D printed tablets [30]. It was expected that in vitro hydrochlorothiazide release was directly related to surface area/volume. However, the length of the channel appeared to have a significant effect on the extent of drug release. For instance, the use of 18-short channels has been more effective in increasing in vitro drug release at $\mathrm{T}=30 \mathrm{~min}$ compared to the 9-long channel design despite having significantly lower surface/volume ratio (Table 2). Wide-angle green light imaging of the first $10 \mathrm{~min}$ of the dissolution test confirms the surface erosion of $3 \mathrm{D}$ printed tablet during dissolution test in both channel designs (Figure 7). The imaging confirmed a faster erosion from 18-short channels design in comparison to 9 -channels $(44.3 \%$ versus $38.3 \%$ after $\mathrm{T}=10 \mathrm{~min})(p<0.05)$. Previous attempts to modify the internal structure of $3 \mathrm{D}$ printed tablets by modifying the infill percentage $[17,22,45]$. This led to formation of a low density and floating tablets, where the penetration of aqueous medium takes place in a chamber by chamber order. In contrast, the proposed channelled approach allowed the tablet to be immerged in the medium while preserving an easy-to-swallow structure. 

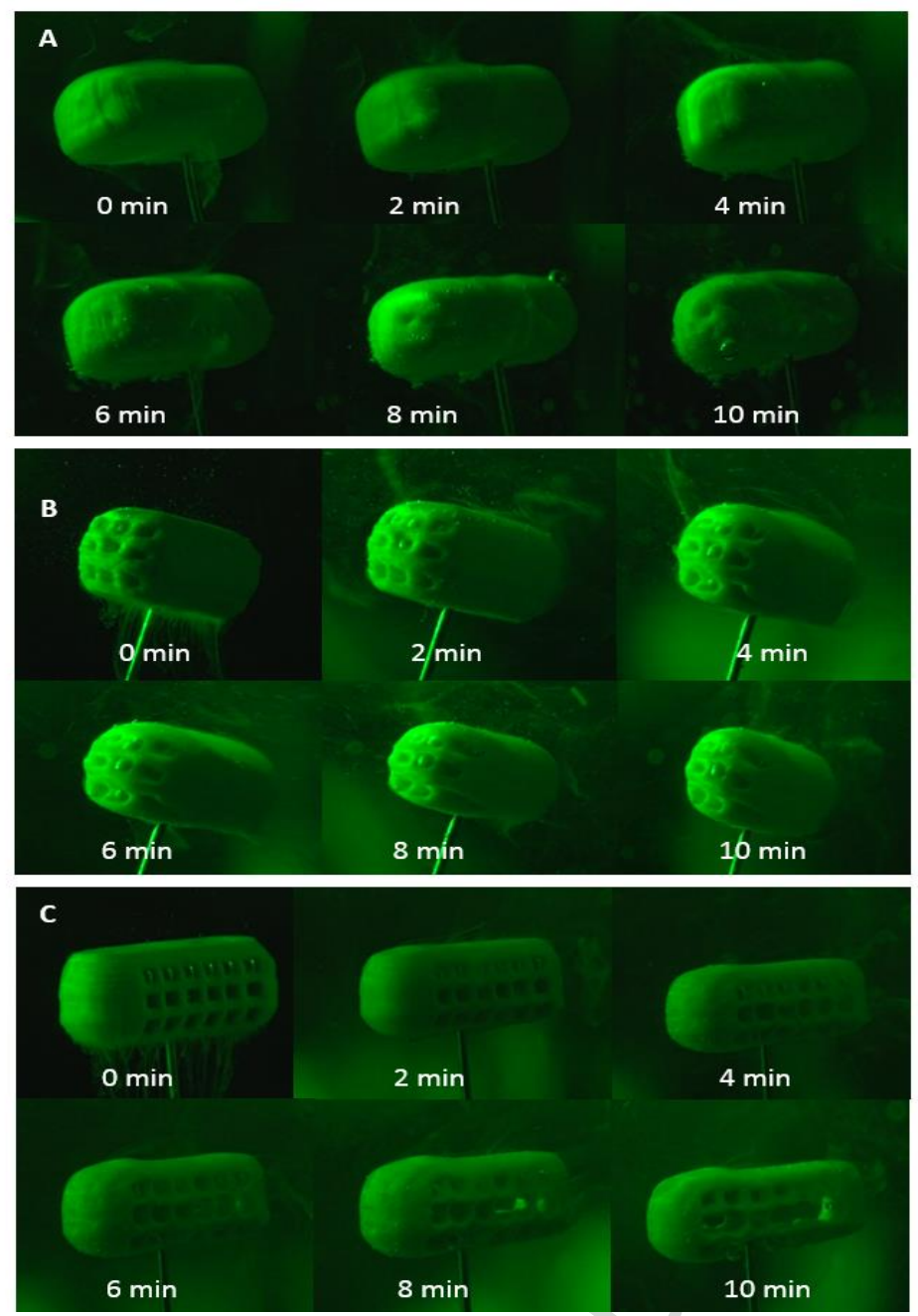

Figure 7. Wide-angle green light imaging during the first $10 \mathrm{~min}$ of USP II dissolution test of 3D printed hydrochlorothiazide tablets with a) solid design, b) long 9 channel design and c) 18 short channel design using mono-colour laser light

The changes in the shape of the channelled tablets during dissolution process have also been monitored at $5 \mathrm{~min}$ intervals (Figure 8). Both tablet designs showed an expansion in the width of the channels during the dissolution process with a progressing decrease in the thickness of inter-channel walls. This has been accompanied by a loss in the square shape of the channel section and the formation of more rounded sections. As the inner diameter of the channel increased, the inter-channel spaces became narrower leading to the fragmentation of the tablet into smaller fractions in the dissolution medium. Such effect is more pronounced in the designs of shorter channels, where inter-channel domains are shorter (Figure 8c). 
a
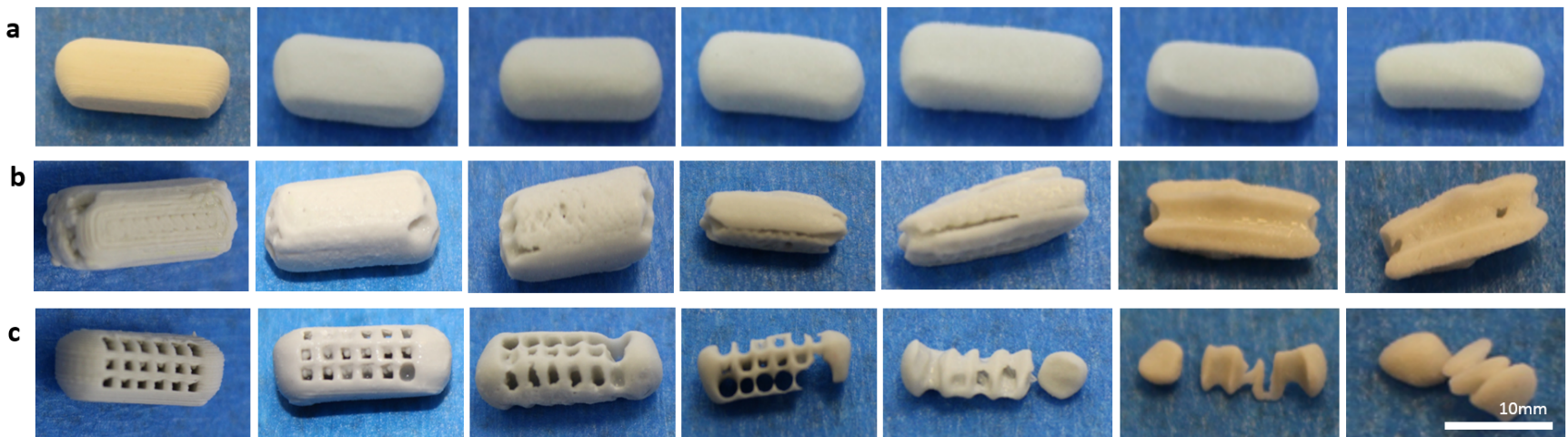

5 min

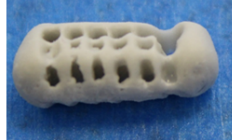

$10 \mathrm{~min}$

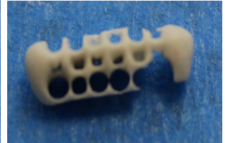

$15 \min$

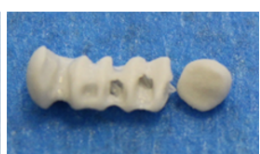

$20 \mathrm{~min}$

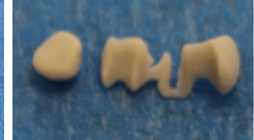

$25 \min$

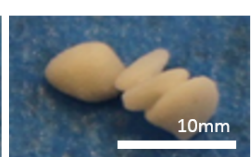

$30 \mathrm{~min}$

Figure 8. Impact of tablet design and channel length on the erosion pattern of $3 \mathrm{D}$ printed tablets. Photograph of 3D printed tablets before and after 5, 10, 15, 20, 25 and 30 min of undertaking USP II dissolution test in gastric medium ( $\mathrm{pH}$ 1.2) with a) solid design, b) long 9 channel design and c) 18 short channel designs.

An important factor that impact the pattern of drug release is the flow of gastric medium through the channels during the dissolution process. The area within channel of $\mathrm{L}$ length and $\mathrm{W}$ width can be expressed as 4WL. If $\eta$ is viscosity of dissolution medium, the force needed to drive the pressure force within the channel. The velocity gradient will be expressed as $\frac{d v}{d w}$ and the pressure force applied to move the channel is $\rho$

And the viscosity force will be $-\eta \frac{d v}{d w} 4 \mathrm{WL}$

$$
\rho \mathrm{w}^{2}=-\mathrm{\eta} \frac{d v}{d w} 4 \mathrm{WL}
$$

The longer the channel the higher the hydraulic forces needed to allow drug flow.

However, the significant reduction in the length of the channel in tablets with shorter channel reduces the friction surface area leading to a faster flow of the medium. It is also important to highlight that with erosion of methacrylate matrix, the width of the channel, W will be increased, leading to a reduction in the resistance to flow and accelerating the flow rate, hence leading to a faster drug release. It is also worth noting that channelling system is more suitable to non-swelling systems as a swellable polymer matrix might lead to narrowing or closure of channels upon introduction to aqueous medium.

In summary, this work clearly demonstrated the potential of channelled system in modifying the release and fragmentation pattern of FDM 3D printed tablets. With development of novel 
materials and significant improvement in the resolution and accuracy of future 3D printing technologies [46], we anticipate that $\mathrm{CAD}$ will allow production of more detailed structures with different mechanical and drug release functionality from established polymeric matrices..

\section{Conclusions}

We have presented an alternative novel design approach through engineering perforating channels within the tablet design. This complex structure design does not only increase the surface area of the tablet, but also facilitate media perforation through the structure. A channel size of $\geq 0.6 \mathrm{~mm}$ is essential to accelerate the drug release and meet pharmacopeial criterion for immediate release products. The use of large number of shorter channels proved more efficient in accelerating drug release from the tablet than longer channels. This has been attributed to the reduced resistance to flow and faster fragmentation of the tablet of shorter channels during dissolution test. The incorporation of short channels can be adopted in the designs of dosage forms, implants or stents to enhance the release rate of eluting drug from rich polymeric structures. It is anticipated that a new generation of dosage form of complex geometry will emerge to tailor drug release via controlling the media flow through these built-in channels.

\section{Acknowledgments}

The authors would like to thank UCLan Innovation Team for this support and Mrs Reem Arafat for her help with graphics design. 


\section{References}

[1] GBIResearch, Oral drug delivery market report, http://www.contractpharma.com/issues/2012-06/view_features/oral-drug-delivery-market-report/ (16/7/2017), 2012.

[2] Marketsandmarkets, Drug delivery technology market, http://www.marketsandmarkets.com/Market-Reports/drug-delivery-technologies-market1085. html?gclid=CIXRuMT5osQCFe6WtAodmiUAZg (16/7/2017), 2013.

[3] H. Bär, The role and importance of controlled release in the global pharmaceutical market -a review, 11th International Controlled Release Seminar, 2017.

[4] F. Ferrari, M. Bertoni, C.M. Bonferoni, S. Rossi, C. Caramella, G.K. Bolhuis, Dissolution enhancement of an insoluble drug by physical mixture with a superdisintegrant:optimization with a simplex lattice design, Pharm Dev Technol, 1(1996) 159-164.

[5] V. Sekar, V.R. Chellan, Immediate release tablets of tel misartan using superdisintegrantformulation, evaluation and stability studies, Chem Pharm Bull (Tokyo), 56 (2008) 575-577. [6] N. Zhao, L.L. Augsburger, The influence of product brand-to-brand variability on superdisintegrant Performance. A case study with croscarmellose sodium, Pharm Dev Technol, 11 (2006) 179-185.

[7] E. Freye, J.V. Levy, D. Braun, Effervescent morphine results in faster relief of breakthrough pai $n$ in patients compared to immediate release morphine sulfate tablet, Pain Pract, 7(2007) 324-331.

[8] S. He, F. Li, D. Zhou, J. Du, Y. Huang, Formulation and evaluation of novel coated floating tablets of bergenin and cetirizine dihydrochloride for gastric delivery, Drug Dev Ind Pharm, 38 (2012) 12801288.

[9] K. Wening, E.J. Laukamp, M. Thommes, J. Breitkreutz, Individual oral therapy with immediate release and effervescent formulations delivered by the solid dosage pen, J Pers Med, 2 (2012) 217231.

[10] C. Benetti, L. Flammini, V. Vivo, P. Colombo, G. Colombo, L. Elviri, C. Scarpignato, F. Buttini, R. Bettini, E. Barocelli, A. Rossi, Esomeprazole immediate release tablets: Gastric mucosa ex vivo permeation, absorption and antisecretory activity in consci ous rats, J Control Release, 239 (2016) 203-210.

[11] T. Bishop, The Colorful History of Pills Can Fill Many a Tablet, The Chemist and Druggist, (1954).

[12] G.C. Cole, Introduction and overview of pharmaceutical coating, in: G.C. Cole (Ed.) Pharmaceutical Coating Technology, Taylor \& Francis Ltd 1, London, 1995.

[13] B.M. Wu, S.W. Borland, R.A. Giordano, L.G. Cima, E.M. Sachs, M.J. Cima, Solid free-form fabrication of drug delivery devices, J Control Release, 40 (1996) 77-87.

[14] S. McMains, Layered manufacturing technologies, Commun. ACM, 48 (2005) 50-56.

[15] W.E. Katstra, R.D. Palazzolo, C.W. Rowe, B. Giritlioglu, P. Teung, M.J. Cima, Oral dosage forms fabricated by Three Dimensional Printing ${ }^{\mathrm{TM}}$, J Control Release, 66 (2000) 1-9.

[16] D.G. Yu, X.X.Shen, C. Branford-White, L.M. Zhu, K. White, X.L. Yang, Novel oral fastdisintegrating drug delivery devices with predefined inner structure fabricated by Three -Dimensional Printing, J Pharm Pharmacol, 61 (2009) 323-329.

[17] A. Goyanes, A.B. Buanz, A.W. Basit, S. Gaisford, Fused-filament 3D printing (3DP) for fabrication of tablets, Int J Pharm, 476 (2014) 88-92.

[18] J. Skowyra, K. Pietrzak, M.A. Alhnan, Fabrication of extended-release patient-tailored prednisolone tablets via fused deposition modelling (FDM) 3D printing, EurJ Pharm Sci, 68 (2015) 11-17.

[19] A. Melocchi, F. Parietti, A. Maroni, A. Foppoli, A. Gazzaniga, L. Zema, Hot-melt extruded filaments based on pharmaceutical grade polymers for 3D printing by fused deposition modeling, Int J Pharm, 509 (2016) 255-263.

[20] M.A. Alhnan, T.C. Okwuosa, M. Sadia, K.W. Wan, W. Ahmed, B. Arafat, Emergence of 3D Printed Dosage Forms: Opportunities and Challenges, Pharm Res, 33 (2016) 1817-1832. 
[21] K. Pietrzak, A. Isreb, M.A. Alhnan, A flexible-dose dispenser for immediate and extended release 3D printed tablets, EurJ Pharm Biopharm, 96 (2015) 380-387.

[22] X. Chai, H. Chai, X. Wang, J. Yang, J. Li, Y. Zhao, W. Cai, T. Tao, X. Xiang, Fused Deposition Modeling (FDM) 3D Printed Tablets for Intragastric Floating Delivery of Domperidone, Sci Rep, 7 (2017) 2829.

[23] A. Goyanes, A.B. Buanz, G.B. Hatton, S. Gaisford, A.W. Basit, 3D printing of modified-release aminosalicylate (4-ASA and 5-ASA) tablets, EurJ Pharm Biopharm, 89 (2015) 157-162.

[24] A. Goyanes, H. Chang, D. Sedough, G.B. Hatton, J. Wang, A. Buanz, S. Gaisford, A.W. Basit, Fabrication of controlled-release budesonide tablets via desktop (FDM) 3D printing, Int J Pharm, 496 (2015) 414-420.

[25] A. Goyanes, J. Wang, A. Buanz, R. Martinez-Pacheco, R. Telford, S. Gaisford, A.W. Basit, 3D Printing of Medicines: Engineering Novel Oral Devices with Unique Design and Drug Release Characteristics, Mol Pharm, 12 (2015) 4077-4084.

[26] S.A. Khaled, J.C. Burley, M.R. Alexander, C.J. Roberts, Desktop 3D printing of controlled release pharmaceutical bilayer tablets, Int J Pharm, 461 (2014) 105-111.

[27] J. Zhang, X. Feng, H. Patil, R.V. Tiwari, M.A. Repka, Coupling 3D printing with hot-melt extrusion to produce controlled-release tablets, Int J Pharm, 519 (2017) 186-197.

[28] T.C. Okwuosa, D. Stefaniak, B. Arafat, A. Isreb, K.W. Wan, M.A. Alhnan, A LowerTemperature FDM 3D Printing for the Manufacture of Patient-Specific Immediate Release Tablets, Pharm Res, 33 (2016) 2704-2712.

[29] M. Sadia, A. Sosnicka, B. Arafat, A. Isreb, W. Ahmed, A. Kelarakis, M.A. Alhnan, Adaptation of pharmaceutical excipients to FDM 3D printing for the fabrication of patient-tailored immediate release tablets, Int J Pharm, 513 (2016) 659-668.

[30] A. Goyanes, P. Robles Martinez, A. Buanz, A.W. Basit, S. Gaisford, Effect of geometry on drug release from 3D printed tablets, Int J Pharm, 494 (2015) 657-663.

[31] T. Tagami, K. Fukushige, E. Ogawa, N. Hayashi, T. Ozeki, 3D Printing Factors Important for the Fabrication of Polyvinylalcohol Filament-Based Tablets, Biol Pharm Bull, 40 (2017) 357-364.

[32] P. Sanphui, V.K. Devi, D. Clara, N. Malviya, S. Ganguly, G.R. Desiraju, Cocrystals of Hydrochlorothiazide: Solubility and Diffusion/Permeability Enhancements through Drug-Coformer Interactions, Mol Pharm, 12 (2015) 1615-1622.

[33] P. Sanphui, L. Rajput, Tuning solubility and stability of hydrochlorothiazide co-crystals, Acta Crystallogr B Struct Sci Cryst Eng Mater, 70 (2014) 81-90.

[34] B. Sipos, K. Pintye-Hodi, Z. Konya, A. Kelemen, G. Regdon, Jr., T. Sovany, Physicochemical characterisation and investigation of the bonding mechanisms of API-titanate nanotube composites as new drug carrier systems, Int J Pharm, 518 (2017) 119-129.

[35] S.H. Yalkowsky, D. R.M., Aquasol Database of Aqueous Solubility, in: College of Pharmacy, University of Arizona, Tucson, AZ 1992.

[36] L. Dierickx, L. Saerens, A. Almeida, T. De Beer, J.P. Remon, C. Vervaet, Co-extrusion as manufacturing technique for fixed-dose combination mini-matrices, Eur J Pharm Biopharm, 81 (2012) 683-689.

[37] T.D. Reynolds, S.H. Gehrke, A.S. Hussain, L.S. Shenouda, Polymer erosion and drug release characterization of hydroxypropyl methylcellulose matrices, Journal of Pharmaceutical Sciences, 87 (1998) 1115-1123.

[38] A. Banerjee, P.R. Verma, S. Gore, Controlled porosity solubilitymodulated osmotic pump tablets of gliclazide, AAPS PharmSciTech, 16 (2015) 554-568.

[39] M.A. Repka, K. Gutta, S. Prodduturi, M. Munjal, S.P. Stodghill, Characterization of cellulosichotmelt extruded films containing lidocaine, Eur J Pharm Biopharm, 59 (2005) 189-196.

[40] H. Yuasa, Y. Takashima, Y. Kanaya, Studies on the development of intragastric floating and sustained release preparation.1. Application of calcium silicate as a floating carrier, Chem Pharm Bull, 44 (1996) 1361-1366. 
[41] U. Shah, L. Augsburger, Multiple sources of sodium starch glycolate, NF: Evaluation of functional equivalence and development of standard performance tests, Pharmaceutical Development and Technology, 7(2002) 345-359.

[42] X. Han, C. Ghoroi, D. To, Y. Chen, R. Dave, Simultaneous micronization and surface modification for improvement of flow and dissolution of drug particles, Int J Pharm, 415 (2011) 185-195.

[43] N. Rasenack, B.W. Muller, Dissolution rate enhancement by in situ micronization of poorly water-soluble drugs, Pharm Res, 19 (2002) 1894-1900.

[44] T.L. Rogers, A.C. Nelsen, M. Sarkari, T.J. Young, K.P. Johnston, R.O. Williams, 3rd, Enhanced aqueous dissolution of a poorly water soluble drug by novel particle engineering technology: s prayfreezing into liquid with atmospheric freeze-drying, Pharm Res, 20 (2003) 485-493.

[45] A. Goyanes, F. Fina, A. Martorana, D. Sedough, S. Gaisford, A.W. Basit, Development of modified release 3D printed tablets (printlets) with pharmaceutical excipien ts using additive manufacturing, Int J Pharm, 527 (2017) 21-30.

[46] R.L. Truby, J.A. Lewis, Printing soft matter in three dimensions, Nature, 540 (2016) 371-378. 


\section{List of Figures}

Figure 1. Impact of caplet dimensions and inclusion of disintegrant on in vitro drug release from 3D printed tablets (solid design). a) In vitro release of hydrochlorothiazide from different sizes of Eudragit E tablets, $P<0.05$ (mean $\pm \mathrm{SD}, \mathrm{n}=3$ ), b) in vitro release of hydrochlorothiazide from Eudragit E caplets with/without commercially available disintegrants (mean $\pm \mathrm{SD}, \mathrm{n}=3$ ).

Figure 2. Schematic illustration concept of perforating square sectioned channels. The dissolution medium will perforate through the channels and accelerate tablet disintegration and dissolution. The perforating channels were a1) parallel to long axis (9 long channels) or b1) at right angle with the long axis with $3 \mathrm{D}$ max rendered images of frontal, side and top view of channelled tablet designs.

Figure 3. Rendered images of tablet designs with decreasing channel size with a) 9-long channels b) 18-short channels, photographs of tablets with decreasing channel size c) 9 long channels d) 18 short channels.

Figure 4. Visualisation of $\mathrm{X} \mu \mathrm{CT}$ data of 9-long channel design with $1 \mathrm{~mm}$ channel. View of the internal structure of the internal surface of the channel from (a) bottom and (b) top, c) X-Y section and d) Y-Z section of the long channels across the tablets.

Figure 5. Visualisation of $\mathrm{X \mu CT}$ data of 18 -short channel design with $1 \mathrm{~mm}$ channels. a) Side view of the tablet, b) view of the top, c) $\mathrm{X}-\mathrm{Y}$ section and d) $\mathrm{X}-\mathrm{Z}$ section of the channels across the tablets.

Figure 6. Impact on channel width and orientation on dissolution release pattern from hydrochlorothiazide methacrylate tablet in USP II dissolution test in gastric medium $(0.1 \mathrm{M}$ $\mathrm{HCl} \mathrm{pH} 1.2,50 \mathrm{rpm}$. Average $\pm \mathrm{SD})$ a) 18 long tablets, and b) short tablets.

Figure 7. Single light imaging during the first $10 \mathrm{~min}$ of USP II dissolution test of 3D printed hydrochlorothiazide tablets with a) solid design, b) long 9 channel design and c) 18 short channel design using mono-colour laser light

Figure 8. Impact of tablet design and channel length on the erosion pattern of 3D printed tablets. Photograph of 3D printed tablets before and after 5, 10, 15, 20, 25 and 30 min of undertaking USP II dissolution test in gastric medium ( $\mathrm{pH}$ 1.2) with a) solid design, b) long 9 channel design and c) 18 short channel designs. 


\section{List of tables}

Table 1. Measured dimensions, volumes, surface area, surface to volume and surface to mass ratios of $\mathrm{CAD}$ designs of solid tablets (no channels).

Table 2. Measured dimensions, volumes, surface area, surface to volume and surface to mass ratios of $\mathrm{CAD}$ designs of solid and channelled tablets. 


\section{Graphical abstract}
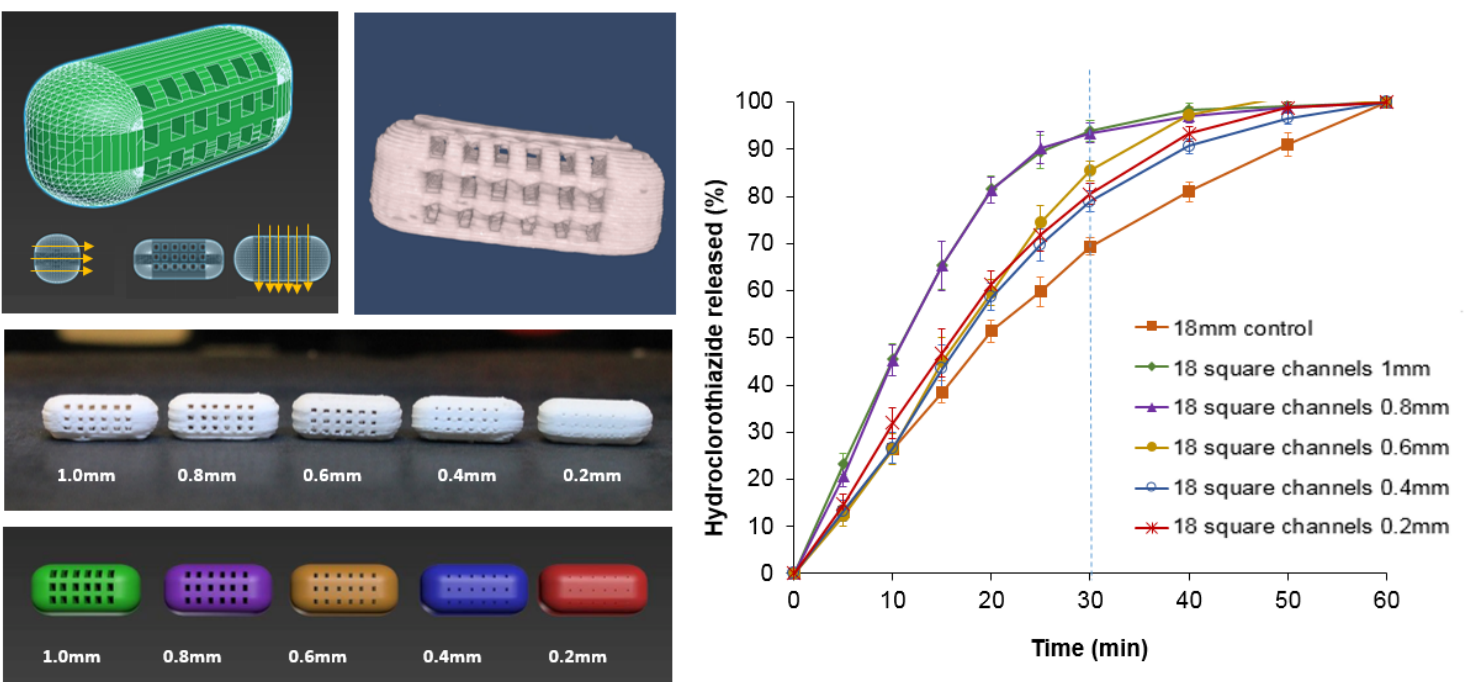